\title{
Ceresbrospinal fluid hypoxanthine and xanthine concentrations as indicators of metabolic damage due to raised intracranial pressure in hydrocephalic children
}

\author{
SD LEVIN, JK BROWN, RA HARKNESS
}

From the University Department of Paediatric Neurology, Royal Hospital for Sick Children, Edinburgh and the Division of Perinatal Medicine, Medical Research Council Research Centre, Northwick Park Hospital, Harrow, UK

SUMMARY Intracranial pressure and cerebrospinal fluid hypoxanthine and xanthine concentrations were measured in hydrocephalic children with suspected raised intracranial pressure. There was a highly significant correlation between intracranial pressure and cerebrospinal fluid hypoxanthine and xanthine levels.

Adenosine triphosphate (ATP) is the main energy currency of the cell. ${ }^{\prime}$ Adenine nucleotides are catabolised during failure of energy supply ${ }^{2}$ to uncharged products which can escape from the cell $^{3-8}$ so that hypoxanthine ${ }^{691015}$ and xanthine ${ }^{15}$ concentrations rise in extracellular fluid, for example, cerebrospinal fluid (CSF). The breakdown of GTP contributes to the related increase in xanthine excretion. ${ }^{22}$ The raised hypoxanthine and xanthine concentrations in CSF from ATP and GTP breakdown in brain can be measured. ${ }^{1314}$ The high and "irreducible" energy consumption of the brain renders it especially vulnerable to failures of oxygen or glucose supply, both of which are reduced in ischaemia. Such ischaemia occurs with raised intracranial pressure (ICP). ${ }^{16}$

Previous studies have shown that brief intracranial pressure monitoring in the awake hydrocephalic patient is likely to produce a false low normal measurement because of the patient's ability to regulate pressure by hyperventilating. ${ }^{18}$ Overnight pressure studies have shown that ICP is highest during REM sleep. ${ }^{19}$ These studies are time-consuming and invasive but may be justified because of limitations in the diagnosis of raised ICP from imaged ventricular dilatation. A biochemical marker indicating that

Address for reprint requests: Dr SD Levin, Dept of Paediatrics, Guy's Hospital, St Thomas's St, London SE1 9RT, UK.

Received 12 December 1983

Accepted 10 January 1984
ICP was sufficiently raised to cause cerebral ischaemia would obviate these difficulties. Our hypothesis was that raised intracranial pressure causes ischaemia by reducing cerebral perfusion pressure and the resulting failure of energy supply would cause metabolic damage which would be reflected in CSF hypoxanthine and xanthine levels.

\section{Patients and methods}

Nineteen hydrocephalic children with suspected raised intracranial pressure underwent 23 recordings. Their ages ranged from 1 year 10 months to 14 years 5 months with a mean of 7 years 7 months. Hydrocephalus had been diagnosed in the first few months of life, usually in association with spina bifida, but other causes included neonatal meningitis (1 case), aqueduct stenosis due to congenital toxoplasmosis (1 case), intraventricular haemorrhage (1 case) and occipital encephalocele (1 case). Most patients had Rickham ventriculostomy reservoirs inserted at the time of their initial ventriculo-peritoneal shunt procedure.

\section{Overnight pressure monitoring}

Patients had ICP monitored via the Rickham reservoir or Pudenz cap. A 21 gauge Huber needle was inserted into the reservoir and this was connected to a Gaeltec* solid state transducer and preamplifier and Bryan's $\dagger$ pen recorder. The mean ICP over one minute during REM sleep was calculated (fig 1). Blood pressure was recorded regularly either with a mercury sphygmamanometer or Dinamap $\ddagger$

*Dunvegan, Isle of Skye, Scotland IV51 9RL

tOrchard Road, Royston, Herts SG8 5HH

‡Simonsen \& Weel Ltd, Hatherley Road, Sicup, Kent DA14 4BR 


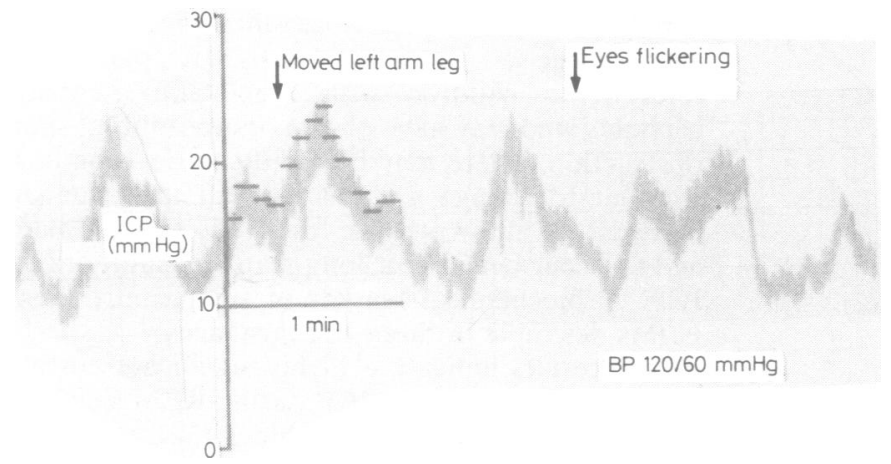

Fig. 1 Portion of overnight intracranial pressure monitoring trace. The patient was in REM sleep defined on clinical and electroencephalographic criteria. Because pressure fuctuated markedly over one minute a mean pressure over this time was calculated using points shown.

oscillometric device. A 3 channel EEG was recorded using an Oxford§ medilog cassette recorder and end expiratory $\mathrm{PCO}_{2}$ was measured continuously via nasal prongs using a Gould Godart \ Capnograph. Sleep staging was done using the continuous EEG trace with clinical observations. Seizure activity, if any, was noted.

At the end of the period of monitoring, ventricular CSF was removed for oxypurine estimations. Within an hour of collection it was centrifuged (2000 g for 5 minutes) if blood-stained and stored in plain plastic tubes. The concentration of intracellular ATP is about $1 \mathrm{mmol} / 1$ whilst extracellular hypoxanthine concentration is about $1 \mu \mathrm{mol} /$ 1. If red cells are not removed, freezing will cause lysis, released ATP will be degraded enzymically and falsely high concentrations of CSF oxypurines recorded. The samples were stored at $-20^{\circ} \mathrm{C}$ until the time of analysis.

Trichloracetic acid extracts of CSF were analysed by high pressure liquid chromatography (HPLC) using the method of Simmonds and Harkness on a C18 Hypersil column. ${ }^{14}$ Absorbance was measured at 254 and $280 \mathrm{~nm}$ and peak identity checked by enzyme incubation. HPLC can separate hypoxanthine and xanthine and is specific and sensitive. ${ }^{13} 14$

\section{Results}

Eighteen satisfactory recordings were obtained allowing calculation of the highest mean pressure during REM sleep. There was a highly significant correlation between hypoxanthine concentration and ICP during REM sleep (fig 2) and xanthine concentration and ICP (fig 3). If individual patient's hypoxanthine and xanthine are added and this total correlated with ICP the correlation is even more significant $(p=0.0000024)$.

In the remaining five recordings and another four incomplete studies it was possible to say that pressure was raised but not to quantitate it. If these cases are included, the results can be summarised as shown in fig 4. From these results it was found that for hypoxanthine no patient with normal or §Oxford Medical Systems, Nuffield Way, Abingdon OX14 1BZ \$Roebuck Road, Hainault, Ilford, Essex IG6 3UE

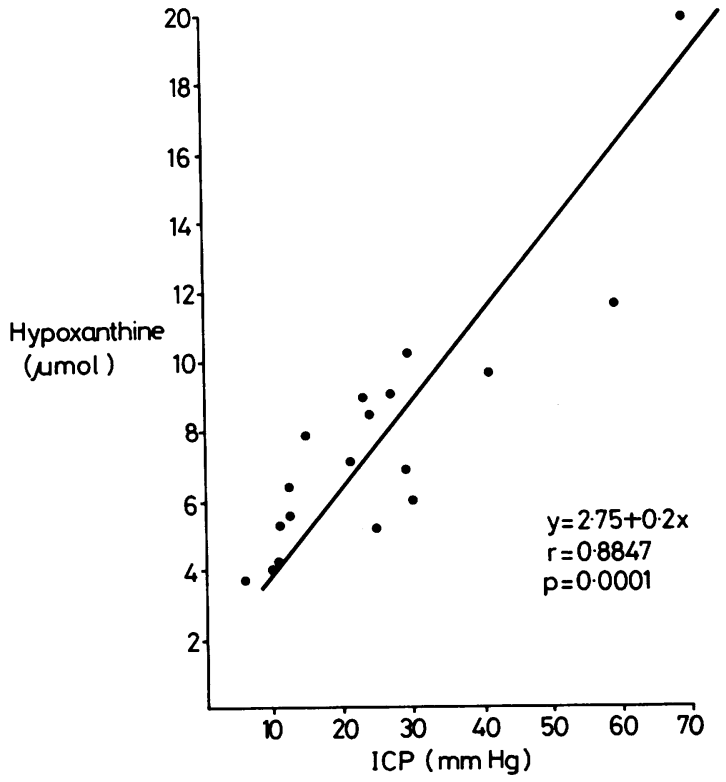

Fig. 2 Correlation of CSF hypoxanthine concentration against mean intracranial pressure over one minute during REM sleep.

equivocal pressure had a level greater than $8 \mu \mathrm{mol} / \mathrm{l}$. With xanthine no patient with normal or equivocal pressure had a level greater than $5 \cdot 1 \mu \mathrm{mol} / \mathrm{l}$. If total oxypurines are considered, that is, hypoxanthine plus xanthine concentration, no patient with normal or equivocal pressures had a level greater than 13 $\mu \mathrm{mol} / \mathrm{l}$.

\section{Discussion}

Raised intracranial pressure may be difficult to diagnose especially if it is low grade or intermittent. Prolonged intracranial pressure monitoring is timeconsuming and technically difficult, whilst the CT 


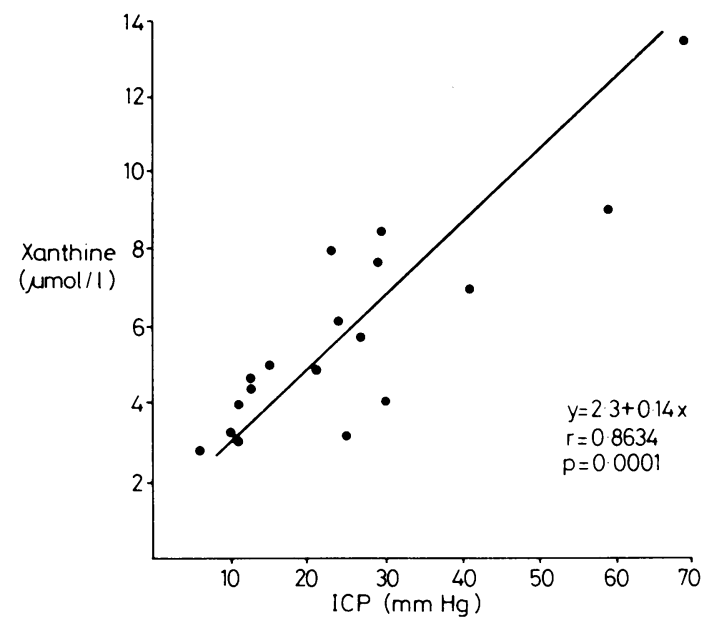

Fig. 3 Correlation of CSF xanthine concentration against mean intracranial pressure over one minute during $R E M$ sleep.

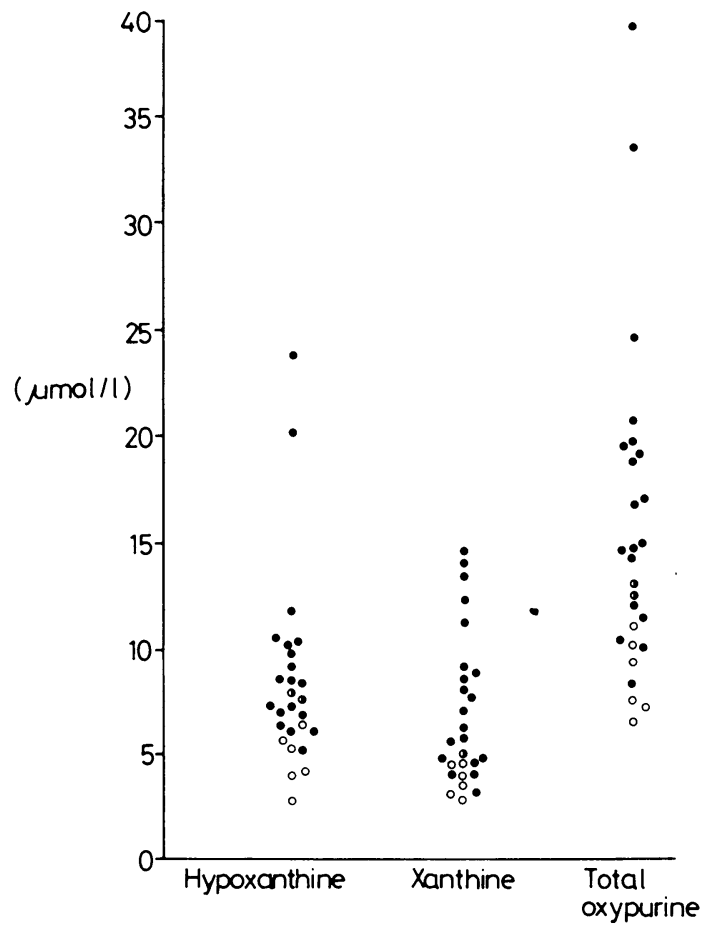

Fig. 4 Concentrations of CSF hypoxanthine, xanthine and total oxypurines in patients with raised ICP, $>20 \mathrm{mmHg}$ (О); equivocal ICP , 13-20 $\mathrm{mmHg}$ (О); and normal ICP, $<13 \mathrm{mmHg}(\mathrm{O})$. No patient with normal or equivocal pressure had a hypoxanthine concentration $>8 \mu \mathrm{mol} / \mathrm{l}$, a xanthine level $>5 \cdot 1 \mu \mathrm{mol} / \mathrm{l}$, or a total oxypurine level $>13 \mu \mathrm{mol} /$ l. scan diagnosis of raised intracranial pressure is late and imprecise. These problems are particularly relevant in children with long-standing hydrocephalus who may have partial or intermittent shunt obstruction. There may be a difficult decision as to whether to change a shunt with all the attendant hazards ${ }^{20}$ or allow possible low grade cerebral damage to occur because of long-standing subtly raised ICP. A biochemical marker of significantly raised ICP is desirable in these circumstances.

Our results indicate a highly significant correlation between maximum ICP during REM sleep and both hypoxanthine and xanthine. Our results are consistent with those in experimental animals ${ }^{916}$ and suggest that the mechanism by which CSF oxypurines are raised in the presence of raised ICP is due to decreased cerebral perfusion pressure causing tissue hypoxia.

No patient with a normal or equivocal ICP had a hypoxanthine level greater than $8 \mu \mathrm{mol} / \mathrm{l}$, a xanthine level greater than $5 \cdot 1 \mu \mathrm{mol} / \mathrm{l}$, or a total oxypurine level greater than $13 \mu \mathrm{mol} / \mathrm{l}$, and we suggest that further studies to prove that these levels are pathological, requiring surgical intervention, are now justified. These figures also suggest that a sensitive method measuring total oxypurine concentrations would be suitable for routine clinical use. Total oxypurine, hypoxanthine plus xanthine, concentrations can be measured in CSF with a $\mathrm{pO}_{2}$ electrode measuring the amount of oxygen that is consumed when hypoxanthine is oxidised to urate in the presence of added xanthine oxidase, " and an improved method has been described. ${ }^{17}$ An enzymatic colour test for total oxypurine has also been described ${ }^{12}$ but these methods are insensitive and for research high pressure liquid chromatography which can separate hypoxanthine and xanthine, is the most specific and sensitive method..$^{1314}$

Some patients with raised ICP have hypoxanthine and xanthine measurements below the levels mentioned previously. This suggests to us that either the episodes of raised pressure are of too short a duration to cause significant ischaemia or that CPP is maintained by other methods, for example, by increasing mean arterial pressure. Patients with reduced compliance may show rapid increases in pressure with changes in cerebral blood flow but accommodate in a relatively short time. Since there is a time factor involved in the production of significant metabolic tissue damage from hypoxia, prolonged low grade intracranial hypertension may cause the same amount of damage as a brief episode of markedly raised ICP.

CSF hypoxanthine and xanthine levels appear specifically to reflect the initial metabolic damage from failure of energy supply ${ }^{21}$ and could thus indi- 
cate significantly raised intracranial pressure.

Whilst raised CSF oxypurines may prove useful in selecting those patients requiring shunt revision, there is a need for a controlled trial in which CT scan appearances, intracranial pressure monitoring and oxypurine levels are evaluated against long-term progress including psychometric assessment of both treated patients and those with supposedly arrested or adequately controlled hydrocephalus. Oxypurine measurements may then be found to simplify the diagnosis and management of raised intracranial pressure not only in cases such as ours but also in other situations.

The work was undertaken under the rules of the Royal Hospital for Sick Children, Edinburgh, Ethical Committee.

SDL was a Research Fellow in the Department of Child Life and Health, University of Edinburgh, supported by a grant from the special fund administered by Mr George Pollock FRCS. We thank the nursing staff of Wards 2 and 7, Royal Hospital for Sick Children, Edinburgh, Mrs Deirdre Gillies for typing the manuscript, and the Department of Medical Illustration and Photography, Guy's Hospital, for preparing the illustrations.

\section{References}

${ }^{1}$ Atkinson DE. Cellular Energy Metabolism and its Regulation. London, Academic Press, 1977.

${ }^{2}$ Berne RM. Cardiac nucleotides: possible role in regulation of coronary flow. Am J Physiol 1963;204:31722.

${ }^{3}$ Drews LR, Gilboe DD, Betz AL. Metabolic alterations in brain during anoxic anoxia and subsequent recovery. Arch Neurol 1973;29:385-90.

${ }^{4}$ Nordstrom CH, Rehncrona S, Siesjo BK, Westerberg E. Adenosine in rat cerebral cortex: its determination, normal values, and correlation to AMP and cyclic AMP during shortlasting ischemia. Acta Physiologica Scand 1977;101:63-71.

${ }^{5}$ Deuticke B, Gerlach E. Abbau freier nucleotide in herz, skeletmuskel, gehirn und leber der ratte bei sauer stoffmangel. Arch Ges Physiol (Pfuger's) 1966;292:239-54.

- Berne RM, Rubio R, Curnish RR. Release of adenosine from ischaemic brain. Effect on cerebral vascular resistance and incorporation into cerebral adenine nucloetides. Circ Res 1974;35:262-71.

${ }^{7}$ Winn HR, Rubio R, Berne RM. Brain adenosine pro- duction in the rat during 60 seconds of ischaemia. Circ Res 1979;45:486-92.

${ }^{8}$ Saugstad OD. Hypoxanthine as an indicator of tissue hypoxia. J Oslo City Hosp 1977;27:29-40.

9 Saugstad OD, Schrader H, Aase AO. Alteration of the hypoxanthine level in cerebrospinal fluid as an indicator of tissue hypoxia. Brain Res 1976;112:188-9.

${ }^{10}$ Meberg A, Saugstad OD. Hypoxanthine in cerebrospinal fluid in children. Scand J Clin Lab Invest 1978;38:437-40.

" Saugstad OD. The determination of hypoxanthine and xanthine with a $\mathrm{pO}_{2}$ electrode. Pediatr Res 1975;9:575-9.

12 Von Maaser M, Schramm D, Schedit B, Frenzel J. Methodischer beitrag zur bestimmung von hypoxanthin im serum als hypoxieparameter bei neugebornen. Kinderarztl Prax 1979;47:408-13.

${ }^{13}$ Harkness RA, Simmonds RJ, O'Connor MC, Webster ADB. Purine metabolism studied with high pressure liquid chromatography. Biochem Soc Trans 1979; 7:1021-2.

${ }^{14}$ Simmonds RJ, Harkness RA. High performance liquid chromatographic methods for base and nucleoside analysis in extracellular fluids and in cells. $J$ Chromatogr 1981;226:369-81.

is Harkness RA, Lund RJ. Cerebrospinal fluid concentrations of hypoxanthine, xanthine, uridine and inoxine: high concentrations of the ATP metabolite, hypoxanthine, after hypoxia. J Clin Pathol 1983;36:1-8.

${ }^{16}$ Siesjo BK. Brian Energy Metabolism. Chichester: John Wiley and Sons, 1978.

${ }^{17}$ Manzke H, Spreter V, Kreudenstein P, Dorner K, Kruser K. Quantitative measurements of the urinary excretion of creatinine, uric acid, hypoxanthine and xanthine, uracil, cyclic AMP and cyclic GMP in healthy newborn infants. Eur J Ped 1980;133:157-61.

${ }^{18}$ Levin SD, Minns RA, Steer CR, Brown JK. Relationships of $\mathrm{pCO}_{2}$ to intracranial pressure in hydrocephalic children. In preparation.

${ }^{19}$ Pierre-Kahn A, Gabersek V, Hirsch JF. Intracranial pressure and rapid eye movement sleep in hydrocephalus. Child's Brain 1976;2:156-66.

${ }^{20}$ Olsen L, Frykberg T. Complications in the treatment of hydrocephalus in children. Acta Paediatr Scand 1983;72:385-90.

${ }^{21}$ Harkness RA, Simmons RJ, Coade SB, Lawrence CR. Ratio of the concentration of hypoxanthine to creatinine in urine from newborn infants: a possible indicator for the metabolic damage due to hypoxia. $\mathrm{Br}$ J Obstet Gynaecol 1983;90:447-52.

${ }^{22}$ Harkness RA, Coade SB, Walton KR, Wright D. Xanthine oxidase deficiency and "Dalmatian" hypouricaemia: effect of exercise and incidence. $J$ Int Metab Dis 1983; in press. 